\title{
Consumo, digestibilidade dos nutrientes e parâmetros ruminais em bovinos alimentados com silagem de capim-mombaça
}

[Intake, digestibilities of the nutrients, and ruminal variables in cattle fed Mombaça-grass silage]

\author{
B.R. Vieira ${ }^{1}$, J.A. Obeid ${ }^{2}$, O.G. Pereira ${ }^{2}$, S.C. Valadares Filho ${ }^{2}$, I.P.C. Carvalho ${ }^{1}$, J.A.G. Azevedo ${ }^{3}$ \\ ${ }^{1}$ Faculdade de Ciências Agrárias e Veterinárias - UNESP - Jaboticabal, SP \\ ${ }^{2}$ Departamento de Zootecnia - UFV - Viçosa, MG \\ ${ }^{3}$ Universidade Estadual de Santa Cruz - Ilhéus, BA
}

\begin{abstract}
RESUMO
Avaliaram-se o consumo, a digestibilidade aparente total e parcial dos nutrientes, o pH e a concentração de amônia ruminal em bovinos alimentados com silagem de capim-mombaça e concentrado nas seguintes proporções: 80:20, 65:35, 50:50 e 35:65, com base na matéria seca. Foram utilizados quatro animais Holandês x Zebu, com peso corporal médio inicial de $229 \mathrm{~kg}$, canulados no rúmen e abomaso, e distribuídos em quadrado latino $4 \times 4$. Os consumos de matéria seca (MS), matéria orgânica (MO), proteína bruta (PB), extrato etéreo (EE) e carboidratos totais (CHOT), expressos em $\mathrm{kg} / \mathrm{dia}$, e a digestibilidade parcial dos carboidratos não fibrosos (CNF) apresentaram comportamento linear crescente, com resposta platô nos níveis de concentrado de 54,1;54,8;52,9;62,2;55,2 e 52,7\%. O consumo dos demais nutrientes, exceto da fibra em detergente neutro (FDN), e as digestibilidades aparente total de MS, MO e CNF e a parcial de MO aumentaram linearmente com o incremento do concentrado nas dietas. Não foram encontradas diferenças no consumo e nas digestibilidades aparente total e parcial da FDN. Para concentração de amônia e pH ruminal, observou-se efeito quadrático de tempo de amostragem, com valores máximos de 24,76mg/dL e 6,53 em 2,8 e 3,5 horas após a alimentação, respectivamente.
\end{abstract}

Palavras-chave: matéria seca, digestibilidade ruminal, fibra em detergente neutro, óxido crômico

\begin{abstract}
Intake; total and partial digestibilities of nutrients; and ruminal $\mathrm{pH}$ and ammonia concentration were evaluated in beef cattle fed Mombaça-grass silage and concentrate at the following proportions: 80:20, 65:35, 50:50, and 35:65, in the dry matter basis. Four Holstein $x$ Zebu steers, with average live weight of $229 \mathrm{~kg}$, fitted with ruminal and abomasal canullae, were used. The animals were allotted in a $4 \times 4$ latin square design. The intakes of dry matter (DM), organic matter (OM), crude protein $(C P)$, ether extract $(E E)$, and total carbohydrates ( $\mathrm{kg} /$ day), as well the partials digestibilities of non fibrous carbohydrates $(N F C)$ increased linearly with plateau at the concentrate levels of 54.1, 54.8, 52.9, 62.2, 55.2, and 52.7\%. The intakes of others nutrients, except neutral detergent fiber (NDF), and the total apparent digestibilities of DM, OM, and NFC and the partial digestibility of OM increased linearly as the concentrate levels in the diets increased. No differences were found on the intake and the total and partial apparent digestibilities of NDF. The ruminal $\mathrm{pH}$ and ammonia concentration presented a quadratic affect in relation to the time of sampling, with maximum register at 2.8 and 3.5 hours after feeding, respectively, corresponding to $\mathrm{pH} 6.53$ and $24.76 \mathrm{mg} / \mathrm{dL}$ of ammonia.
\end{abstract}

Keywords: dry matter, ruminal digestibility, neutral detergent fiber, chromic oxide

Recebido em 12 de agosto de 2009

Aceito em 20 de agosto de 2010

E-mail: ramalhovieira@yahoo.com.br 


\section{INTRODUÇÃO}

A utilização de forrageiras conservadas, principalmente na forma de silagem, para animais em confinamento, é uma alternativa que garante o fornecimento de forragem de alta qualidade durante os períodos de seca e escassez de alimentos. Embora milho, sorgo, milheto, girassol e capimelefante sejam, atualmente, as forrageiras mais utilizadas na produção de volumosos conservados, a produção de silagens de gramíneas tropicais perenes, confeccionadas a partir do próprio pasto, tem se mostrado uma alternativa viável e segura de produção de volumosos.

O consumo, relacionado diretamente ao aporte de nutrientes e, consequentemente, determinante no atendimento das exigências nutricionais, é considerado a principal variável que influencia no desempenho animal (Mertens, 1994; Van Soest, 1994) e, juntamente com a digestibilidade e a eficiência energética, constitui os parâmetros mais importantes relacionados com a qualidade do alimento.

A determinação da concentração de amônia possibilita avaliar o balanceamento de proteína da dieta, visto que altos níveis de amônia estão associados ao excesso de proteína ou à baixa concentração de carboidratos degradáveis no rúmen (Ribeiro et al., 2001). Outro parâmetro importante é o pH ruminal, que deve ser mantido próximo à neutralidade, sendo que sua variação está relacionada à frequência de alimentação, à adaptação à dieta e à quantidade de carboidratos prontamente fermentáveis.

Vários são os estudos que envolveram a alimentação de bovinos com dietas que continham diferentes níveis de concentrado, mas os que utilizaram silagens de gramíneas não convencionais, como as do gênero Panicum, são escassos. O capim-mombaça possui grande potencial de produção por área e elevado valor nutritivo.

Neste contexto, este trabalho foi realizado com o objetivo de avaliar os consumos e as digestibilidades aparentes totais e parciais dos nutrientes, o pH, a concentração de amônia ruminal de bovinos de corte que receberam dietas que continham silagem de capim-mombaça, Panicum maximum cv., e concentrado em diferentes proporções.

\section{MATERIAL E MÉTODOS}

O experimento foi realizado na Central de Experimentação, Pesquisa e Extensão do Triângulo Mineiro (CEPET), da Universidade Federal de Viçosa. A CEPET localiza-se no município de Capinópolis-MG, com altitude média de 620,2m. Segundo a classificação de Köppen (1948), o clima é do tipo Aw, quente e úmido, com temperatura mínima do mês mais frio acima de $18^{\circ} \mathrm{C}$, apresentando precipitações médias anuais entre 1400 e $1600 \mathrm{~mm}$.

Foram utilizados quatro novilhos mestiços Holandês x Zebu, com média de peso vivo inicial de $229 \mathrm{~kg}$, canulados no rúmen e abomaso, e distribuídos em um quadrado latino $4 \times 4$. Os tratamentos $(\mathrm{T})$ consistiram de dietas com $13,0 \%$ de proteína bruta, contendo as seguintes proporções de silagem de capim-mombaça e concentrado, com base na matéria seca: T1- 80:20; T2- 65:35; T350:50 e T4- 35:65. Os concentrados eram compostos de grão de milho moído, farelo de soja, ureia/SA, calcário, cloreto de sódio, fosfato bicálcico e premix mineral. A composição químicobromatológica dos alimentos e das dietas encontram-se nas Tab. 1 e 2, respectivamente.

$\mathrm{O}$ alimento foi fornecido às 8 e $15 \mathrm{~h}$, de forma a manter sobras de $10 \%$ do total fornecido. Os animais foram pesados ao início e ao final de cada período experimental, num total de quatro períodos, com duração de 20 dias cada, sendo 10 dias para adaptação dos animais às dietas e 10 dias destinados às coletas. Durante o período experimental, foram obtidas amostras de silagem, com intervalos de três dias, para medições de $\mathrm{pH}$ e $\mathrm{N}$-amoniacal, conforme técnica descrita por Bolsen et al. (1992).

Para determinação da excreção fecal e do fluxo de digesta abomasal, foi utilizado o óxido crômico $\left(\mathrm{Cr}_{2} \mathrm{O}_{3}\right)$ como indicador, administrado em uma única dose diária de $15 \mathrm{~g}$, via fístula ruminal, às $11 \mathrm{~h}$ da manhã, entre o terceiro e $16^{\circ}$ dias de cada período experimental. As coletas de fezes e de digesta abomasal foram realizadas de 26 em 26 horas, iniciando-se às $8 \mathrm{~h}$, entre o $11^{\circ}$ e $16^{\circ}$ dias de cada período experimental. Para estimar a taxa de passagem, foi utilizada uma dose única de $20 \mathrm{~g}$ de $\mathrm{Cr}_{2} \mathrm{O}_{3}$, via fístula ruminal, às $7 \mathrm{~h}$ do $18^{\circ}$ dia de cada período experimental. As amostras de digesta ruminal foram coletadas antes do fornecimento do indicador e às três, seis, nove, 12, 24, 36 e 48h após a sua administração. 
Tabela 1. Composição químico-bromatológica da silagem e dos concentrados utilizados nas dietas experimentais

\begin{tabular}{lccccc}
\multirow{2}{*}{ Item } & \multirow{2}{*}{ Silagem } & \multicolumn{4}{c}{ Concentrado (\%) } \\
\cline { 3 - 5 } & & 20 & 35 & 50 & 65 \\
\hline Matéria seca (\%) & 28,10 & 95,12 & 95,24 & 93,71 & 94,60 \\
Matéria orgânica $^{1}$ & 88,54 & 93,43 & 93,13 & 93,36 & 93,49 \\
Proteína bruta $^{1}$ & 3,85 & 50,21 & 30,85 & 22,74 & 18,03 \\
NIDN $^{2}$ & 29,34 & 5,80 & 7,71 & 8,60 & 10,28 \\
NIDA $^{2}$ & 14,79 & 2,72 & 3,13 & 4,58 & 6,21 \\
Extrato etereo $^{1}$ & 1,71 & 3,77 & 3,87 & 3,86 & 4,08 \\
CHOT $^{1}$ & 82,98 & 49,35 & 64,06 & 70,72 & 74,42 \\
FDN $^{1}$ & 77,73 & 12,03 & 11,70 & 14,23 & 14,11 \\
FDNi $^{1}$ & 35,23 & 1,29 & 1,18 & 1,30 & 1,44 \\
CNF $^{1}$ & 5,25 & 37,32 & 52,36 & 56,49 & 60,31 \\
FDA $^{1}$ & 47,26 & 5,52 & 3,99 & 3,04 & 3,20 \\
Lignina $^{1}$ & 7,50 & 1,58 & 1,79 & 1,93 & 2,05 \\
\hline
\end{tabular}

1\%) na MS.

${ }^{2}$ Porcentagem na PB total.

NIDN: nitrogênio insolúvel em detergente neutro; NIDA: nitrogênio insolúvel em detergente ácido; CHOT: carboidrato total; FDN: fibra em detergente neutro; FDNi: fibra em detergente neutro insolúvel; CNF: carboidratos não fibrosos; FDA: fibra em detergente ácido.

Em $50 \mathrm{~mL}$ de fluido ruminal, coletado no $17^{\circ}$ dia de cada período experimental, foi realizada a leitura do $\mathrm{pH}$, utilizando-se peagâmetro digital. Após a leitura, as amostras foram acondicionadas em potes plásticos, com $1 \mathrm{~mL}$ de $\mathrm{H}_{2} \mathrm{SO}_{4} 1: 1$, e armazenadas em freezer a $-15^{\circ} \mathrm{C}$, para posterior análise da concentração de amônia ruminal.

O consumo diário foi obtido pela diferença de pesagem do alimento ofertado e das sobras, coletando-se amostras diárias dos alimentos e das sobras por animal. Essas amostras, juntamente com as de fezes, digesta ruminal e abomasal, foram submetidas à pré-secagem a $65^{\circ} \mathrm{C}$, por $72 \mathrm{~h}$, moídas em moinho de faca tipo Willey, com peneira de malha de $1 \mathrm{~mm}$, e armazenadas para análises laboratoriais posteriores, sendo que, para as amostras de fezes e de digesta abomasal, foram confeccionadas amostras compostas por animal em cada período, com base no peso seco.

Ao final do experimento, as amostras dos alimentos, sobras, fezes e digestas abomasais foram submetidas às análises de matéria seca (MS), extrato etéreo (EE), proteína bruta $(\mathrm{PB})$ e matéria orgânica (MO), conforme procedimentos descritos por Silva e Queiróz (2002). Somente para as amostras dos alimentos foram realizadas análises de lignina e de compostos nitrogenados insolúveis em detergente neutro (NIDN) e em detergente ácido (NIDA). O teor de cromo nas fezes foi determinado segundo Williams et al. (1962), utilizando-se espectrofotômetro de absorção atômica.

Tabela 2. Composição químico-bromatológica das dietas experimentais

\begin{tabular}{lcccc}
\hline \multirow{2}{*}{ Item } & \multicolumn{3}{c}{ Concentrado (\%) } \\
\cline { 2 - 5 } & 20 & 35 & 50 & 65 \\
\hline Matéria seca (\%) & 41,51 & 51,60 & 60,91 & 71,32 \\
Matéria orgânica $^{1}$ & 89,52 & 90,15 & 90,95 & 91,76 \\
Proteína bruta $^{1}$ & 13,12 & 13,30 & 13,30 & 13,06 \\
Extrato etéreo $^{1}$ & 2,12 & 2,47 & 2,78 & 3,25 \\
CHOT $^{1}$ & 76,26 & 76,36 & 76,85 & 77,42 \\
FDN $^{1}$ & 64,59 & 54,62 & 45,98 & 36,38 \\
FDNi $^{1}$ & 28,44 & 23,31 & 18,26 & 13,27 \\
$\mathrm{CNF}^{1}$ & 11,67 & 21,74 & 30,87 & 41,04 \\
FDA $^{1}$ & 38,92 & 32,12 & 25,15 & 18,62 \\
Lignina $^{1}$ & 6,32 & 5,50 & 4,72 & 3,96 \\
NDT $^{1}$ & 61,00 & 62,31 & 67,17 & 73,36 \\
\hline
\end{tabular}

${ }^{1}(\%)$ na MS.

CHOT: carboidrato total; FDN: fibra em detergente neutro; FDNi: fibra em detergente neutro insolúvel; CNF: carboidratos não fibrosos; FDA: fibra em detergente ácido; NDT: nutrientes digestíveis totais. 
Os teores de fibra em detergente neutro (FDN) dos alimentos, sobras, fezes e digestas abomasais e de fibra em detergente ácido (FDA) dos alimentos foram determinados pelo método da autoclave, segundo Pell e Schofield (1993). A correção da FDN para cinzas e proteína (FDNcp) foi realizada nas amostras de alimentos, sobras e fezes, para cálculo da digestibilidade da FDN e do NDT das dietas. O NDT das dietas foi calculado segundo equação proposta pelo NRC (Nutrient..., 2001).

Devido à presença de ureia nas dietas, os carboidratos não fibrosos (CNF) dos concentrados foram calculados segundo Hall (2000). As concentrações de $\mathrm{N}-\mathrm{NH}_{3}$ do líquido ruminal foram determinadas mediante destilação com hidróxido de potássio $(\mathrm{KOH}) 2 \mathrm{~N}$, conforme Vieira (1980). O modelo utilizado para obtenção das taxas de passagem (k) foi $\mathrm{o}$ unicompartimental (tempo-independente), de acordo com Ellis et al. (1994).
As variáveis obtidas foram avaliadas por intermédio de análises de variância e regressão, utilizando-se o programa SAS/2001. O pH e a concentração de amônia ruminal foram avaliados em um esquema de parcelas subdivididas, em que as dietas constituíram as parcelas e os tempos de amostragem as subparcelas.

\section{RESULTADOS E DISCUSSÃO}

A silagem do capim-mombaça apresentou

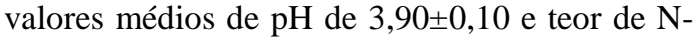
$\mathrm{NH}_{3}$, como porcentagem do $\mathrm{N}$ total, de $5,12 \pm 0,8$, sem a presença de odor desagradável, indicando boa fermentação do material ensilado, segundo características descritas por McDonald et al. (1991) e Muck e Pitt (1993).

$\mathrm{Na}$ Tab. 3, são apresentadas as médias dos consumos diários dos nutrientes e as respectivas equações de regressão, ajustadas em função do nível de concentrado nas dietas e os coeficientes de determinação e de variação.

Tabela 3. Médias dos consumos de matéria seca (MS), matéria orgânica (MO), proteína bruta (PB), extrato etéreo (EE), carboidratos totais (CHOT), fibra em detergente neutro (FDN), carboidratos não fibrosos (CNF), nutrientes digestíveis totais (NDT), equações de regressão ajustadas em função da proporção de concentrado $(\mathrm{C})$ na dieta e coeficientes de determinação $\left(\mathrm{r}^{2}\right)$ e de variação $(\mathrm{CV} \%)$

\begin{tabular}{|c|c|c|c|c|c|c|c|}
\hline \multirow[b]{2}{*}{ Item } & \multicolumn{4}{|c|}{ Concentrado (\%) } & \multirow[b]{2}{*}{ Equação } & \multirow{2}{*}{$r^{2}$} & \multirow{2}{*}{$\begin{array}{l}\text { CV } \\
(\%)\end{array}$} \\
\hline & 20 & 35 & 50 & 65 & & & \\
\hline \multicolumn{8}{|c|}{ Consumo (kg/dia) } \\
\hline MS & 3,63 & 4,53 & 5,53 & 5,77 & $\hat{y} p=2,3516+0,0632168 * C$ & 0,99 & 15,55 \\
\hline MO & 3,24 & 4,08 & 5,03 & 5,30 & $\hat{y} p=2,03196+0,0596383 * C$ & 0,99 & 15,69 \\
\hline PB & 0,56 & 0,67 & 0,80 & 0,80 & $\hat{y} p=0,3977779+0,008049083 * C$ & 0,99 & 13,55 \\
\hline $\mathrm{EE}$ & 0,09 & 0,12 & 0,16 & 0,19 & ŷp $=0,0346759+0,00249842 * C$ & 0,99 & 20,00 \\
\hline CHOT & 2,69 & 3,40 & 4,20 & 4,44 & $\hat{y} p=1,67677+0,0500771 * C$ & 0,99 & 15,91 \\
\hline FDN & 2,22 & 2,31 & 2,28 & 1,83 & $\hat{y}=2,16$ & --- & 16,46 \\
\hline $\mathrm{CNF}$ & 0,49 & 1,10 & 1,92 & 2,61 & $\hat{\mathrm{y}}=-0,50969+0,04796 * * \mathrm{C}$ & 0,99 & 22,26 \\
\hline NDT & 2,21 & 2,84 & 3,73 & 4,19 & $\hat{y}=1,30965+0,04552 * * C$ & 0,99 & 11,72 \\
\hline \multicolumn{8}{|c|}{ Consumo (\% PV) } \\
\hline MS & 1,54 & 1,90 & 2,39 & 2,37 & $\hat{y} p=0,9537302+0,0283059 * C$ & 0,89 & 15,69 \\
\hline FDN & 0,93 & 0,97 & 0,98 & 0,74 & $\hat{\mathrm{y}}=0,91$ & --- & 19,00 \\
\hline NDT & 0,95 & 1,19 & 1,61 & 1,73 & $\hat{y}=0,585580+0,01837^{* *} \mathrm{C}$ & 0,96 & 10,65 \\
\hline
\end{tabular}

** $\mathrm{e}^{*}$ Significativo a 1 e $5 \%$ de probabilidade, respectivamente, pelo teste $\mathrm{F}$. 
Os consumos de MS, MO, PB, EE e carboidratos totais (CHOT), expressos em $\mathrm{kg} / \mathrm{dia}$, e de MS, expressos em \% PV, ajustaram-se a um modelo linear crescente com resposta platô $(\mathrm{P}<0,05)$, estimando-se valores máximos de 5,77; 5,30; 0,$80 ; 0,19 ; 4,44 \mathrm{~kg} /$ dia e $2,4 \%$ PV para as proporções de concentrado de 54,1; 54,8; 52,9; 62,2; 55,1 e 54,6 (Fig. 1), respectivamente. Entretanto, os consumos de CNF e de NDT aumentaram linearmente $(\mathrm{P}<0,01)$, com o
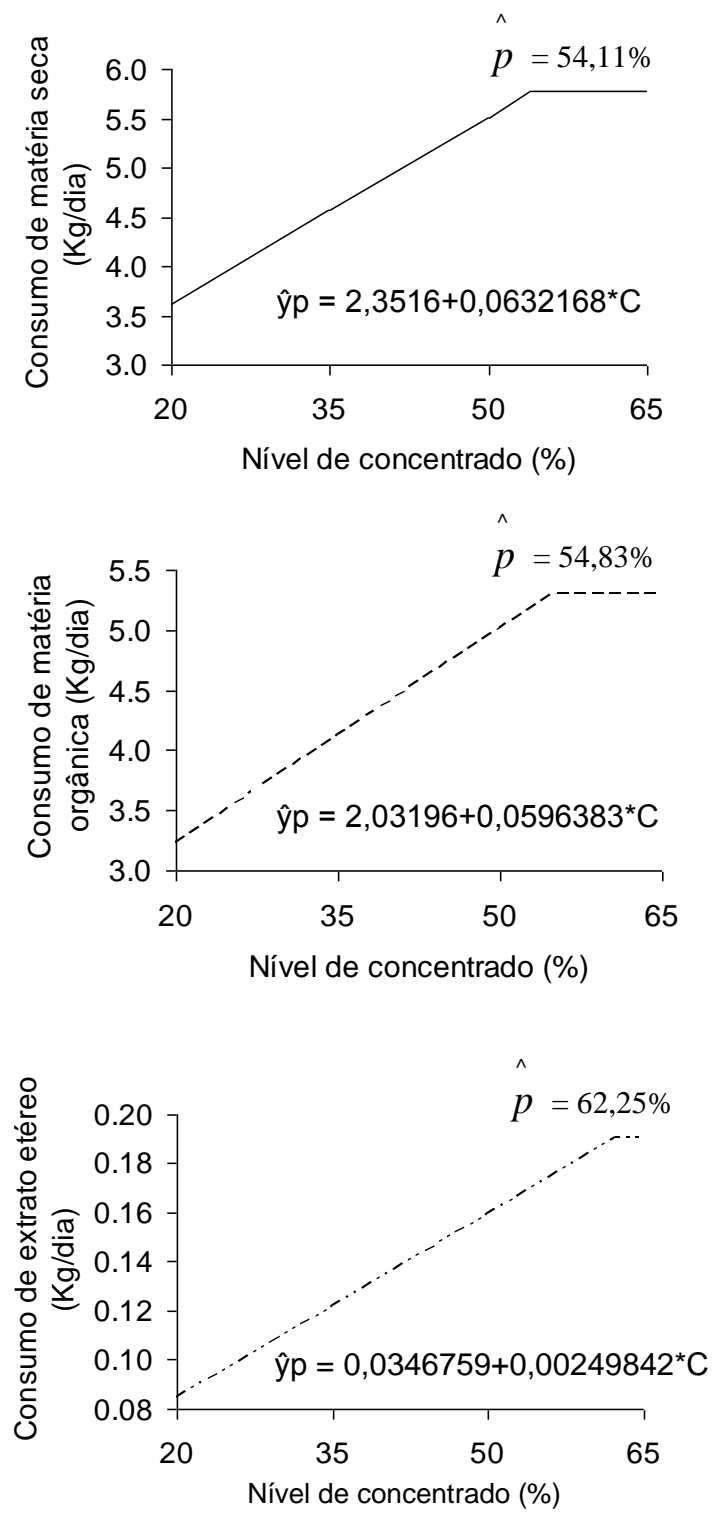

aumento do nível de concentrado nas dietas. Segundo Owens e Goetsch (1993), aumentos da participação de grãos na dieta elevam o consumo, devido à maior densidade física do alimento, à diminuição do tamanho de partícula e a reflexos na velocidade de passagem. Contudo, a resposta ao consumo em dietas à base de silagem e concentrado é muito variável devido, principalmente, ao padrão de fermentação da forragem ensilada.
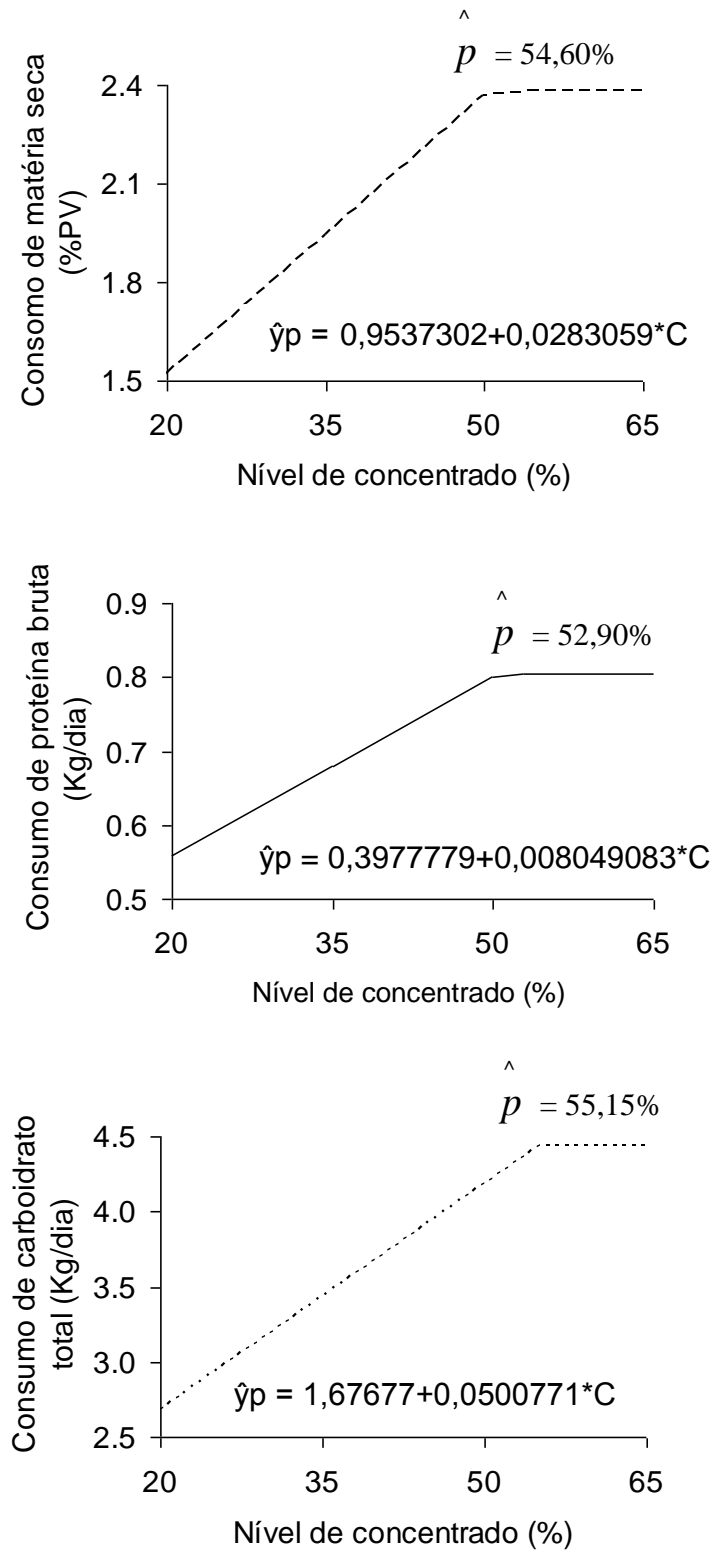

Figura 1. Representação gráfica do efeito linear-platô em função da porcentagem de concentrado nas dietas sobre o consumo de matéria seca, matéria orgânica, proteína bruta, extrato etéreo e carboidratos totais. 
O menor consumo de MS dos animais que receberam dietas que continham $20 \%$ de concentrado correspondeu a $1,54 \%$ do peso vivo (Tab. 3) e pode ser explicado pelo maior teor de FDN, menor teor de CNF e menor teor de MS dessa dieta (Tab. 2), em decorrência da maior proporção de silagem nela existente. Erdman (1993), em artigo de revisão, relata que, quando o conteúdo de MS da dieta total cai abaixo de $50 \%$, o consumo é reduzido aproximadamente $0,5 \%$ para cada unidade percentual de decréscimo no conteúdo de MS.

Silva (2003) relatou aumento linear na ingestão de MS, MO, PB, EE, CNF, CHOT e de NDT em novilhos mestiços, alimentados com silagem de Brachiaria brizantha e concentrado nas mesmas proporções utilizadas no presente trabalho.

Outra explicação para a redução do consumo de MS com o aumento da quantidade de silagem na dieta seria, provavelmente, o maior teor de NDT naquelas dietas que continham porcentagens mais altas de concentrado (Tab. 2), conforme sugeriram Euclides Filho et al. (1997). Assim, aumentos da densidade energética da ração, bem como menores teores de FDN, podem ser apontados como causas do aumento do consumo de MS.

O consumo de FDN, independentemente da forma de expressão, não se ajustou a nenhum modelo (Tab. 3). Devido ao menor teor de FDN nas dietas com maior proporção de concentrado, esperar-se-ia um efeito linear decrescente do consumo desse nutriente, com o aumento do nível de concentrado. Entretanto, esse efeito foi compensado pela maior ingestão de MS nos tratamentos com menor teor de volumoso. Silva et al. (2005) também não detectaram efeito da porcentagem de concentrado sobre o consumo de FDN. Porém, autores como Cardoso et al. (2000) e Gesualdi Jr. et al. (2000) verificaram efeito linear decrescente do consumo de FDN com o aumento da proporção de concentrado na dieta.

$\mathrm{Na}$ Tab. 4, estão relatados os coeficientes de digestibilidade aparente total e parcial dos nutrientes, com suas respectivas equações de regressão, ajustadas em função da porcentagem de concentrado nas dietas, e os coeficientes de determinação e variação.

Tabela 4. Médias das digestibilidades aparentes total, ruminal e intestinal da matéria seca (MS), matéria orgânica $(\mathrm{MO})$, proteína bruta $(\mathrm{PB})$, extrato etéreo $(\mathrm{EE})$, fibra em detergente neutro (FDN) e carboidratos não fibrosos (CNF), respectivas equações de regressão ajustadas em função da porcentagem de concentrado (C) na dieta e coeficientes de determinação $\left(\mathrm{r}^{2}\right)$ e de variação $(\mathrm{CV} \%)$

\begin{tabular}{|c|c|c|c|c|c|c|c|}
\hline \multirow{2}{*}{ Item } & \multicolumn{4}{|c|}{ Concentrado $(\%)$} & \multirow{2}{*}{ Equação } & \multirow{2}{*}{$r^{2}$} & \multirow{2}{*}{$\begin{array}{l}\text { CV } \\
(\%)\end{array}$} \\
\hline & 20 & 35 & 50 & 65 & & & \\
\hline \multicolumn{8}{|c|}{ Digestibilidade aparente total (\%) } \\
\hline MS & 58,36 & 60,76 & 64,82 & 69,21 & $\hat{\mathrm{y}}=52,90792+0,24417 * * \mathrm{C}$ & 0,98 & 4,45 \\
\hline MO & 60,57 & 63,56 & 67,53 & 71,86 & $\hat{\mathrm{y}}=55,16442+0,25212 * * \mathrm{C}$ & 0,99 & 4,07 \\
\hline PB & 77,04 & 76,42 & 75,06 & 77,72 & $\hat{y}=76,56$ & --- & 4,46 \\
\hline $\mathrm{EE}$ & 76,47 & 79,40 & 81,96 & 81,63 & $\hat{y}=79,86$ & --- & 3,76 \\
\hline FDN & 56,14 & 53,95 & 58,96 & 56,26 & $\hat{y}=56,32$ & --- & 4,75 \\
\hline $\mathrm{CNF}$ & 64,94 & 77,14 & 75,22 & 80,47 & $\hat{\mathrm{y}}=61,77775+0,29795 * * \mathrm{C}$ & 0,74 & 5,34 \\
\hline \multicolumn{8}{|c|}{ Digestibilidade aparente ruminal (\%) } \\
\hline $\mathrm{MS}^{1}$ & 65,00 & 69,90 & 73,75 & 73,69 & $\hat{y}=70,59$ & - & 5,44 \\
\hline $\mathrm{MO}^{1}$ & 69,10 & 74,27 & 76,36 & 76,79 & $\hat{y}=67,003660+0,16769 * C$ & 0,85 & 4,18 \\
\hline $\mathrm{PB}^{2}$ & 45,34 & 50,12 & 52,26 & 48,78 & $\hat{y}=49,13$ & --- & 13,89 \\
\hline $\mathrm{EE}^{2}$ & 42,16 & 39,59 & 37,60 & 44,40 & $\hat{y}=40,94$ & --- & 14,66 \\
\hline $\mathrm{FDN}^{1}$ & 84,14 & 92,00 & 82,98 & 84,74 & $\hat{y}=85,97$ & --- & 8,92 \\
\hline $\mathrm{CNF}^{1}$ & 45,94 & 61,22 & 78,03 & 80,64 & $\hat{y} p=24,2947+1,06956 * C$ & 0,99 & 8,79 \\
\hline \multicolumn{8}{|c|}{ Digestibilidade aparente intestinal $(\%)$} \\
\hline $\mathrm{MS}^{1}$ & 35,00 & 30,10 & 26,25 & 26,31 & $\hat{y}=29,41$ & --- & 13,06 \\
\hline $\mathrm{MO}^{1}$ & 30,90 & 25,73 & 23,64 & 23,21 & $\hat{\mathrm{y}}=32,99634-0,16769 * \mathrm{C}$ & 0,85 & 11,98 \\
\hline $\mathrm{PB}^{2}$ & 59,72 & 52,08 & 46,77 & 57,84 & $\hat{y}=54,10$ & --- & 21,42 \\
\hline $\mathrm{EE}^{2}$ & 60,96 & 65,50 & 71,46 & 68,76 & $\hat{y}=66,67$ & --- & 6,41 \\
\hline $\mathrm{FDN}^{1}$ & 15,86 & 8,00 & 17,02 & 15,26 & $\hat{\mathrm{y}}=14,03$ & --- & 54,62 \\
\hline $\mathrm{CNF}^{1}$ & 54,06 & 38,78 & 21,97 & 19,36 & $\hat{\mathrm{y} p}=75,7053-1,06956 * \mathrm{C}$ & 0,99 & 17,42 \\
\hline
\end{tabular}

** e *Significativo a 1 e $5 \%$ de probabilidade, respectivamente, pelo teste $\mathrm{F}$.

${ }^{1}$ Digestibilidade calculada em função do total digestível.

${ }^{2}$ Digestibilidade calculada em função da quantidade que chegou ao local.

(ŷp): Equação da inclinação para resposta linear-platô. 
As digestibilidades aparentes totais da MS e da MO aumentaram linearmente $(\mathrm{P}<0,01)$ com o incremento da proporção de concentrado nas dietas, enquanto, para as digestibilidades aparentes parciais, apenas a MO foi influenciada pela porcentagem de concentrado $(\mathrm{P}<0,05)$. O comportamento linear das digestibilidades totais da MS e MO pode ser explicado pelo aumento do consumo de carboidratos não fibrosos (Tab. 3) com o incremento de concentrado. O aumento da digestibilidade em dietas com porcentagens mais altas de concentrado pode ser atribuído à maior concentração de carboidratos não fibrosos, que são mais digestíveis que os carboidratos fibrosos. Resultados semelhantes foram encontrados por Silva (2003).

As digestibilidades aparentes totais e parciais da PB e EE não foram influenciadas pelo aumento do concentrado. Não foram encontradas, também, diferenças $(\mathrm{P}>0,05)$ nas digestibilidades aparente total, ruminal e intestinal da FDN, sendo observadas as médias de 56,3; 86,0 e
14,0\%, respectivamente (Tab. 4). Carvalho et al. (1997), Cardoso et al. (2000) e Silva (2003) também não encontraram efeito sobre a digestibilidade aparente total da FDN. Entretanto, Resende et al. (2001), Tibo et al. (2000) e Ítavo et al. (2002) observaram efeito linear decrescente com o aumento do concentrado na dieta.

O coeficiente de digestibilidade aparente total dos carboidratos não fibrosos (CNF) aumentou linearmente $(\mathrm{P}<0,01)$ com o incremento de concentrado nas dietas. Entretanto, os coeficientes de digestibilidade aparente ruminal e intestinal dos CNF ajustaram-se ao modelo LRP $(\mathrm{P}<0,05)$, estimando-se digestibilidades máximas e mínimas de 80,6 e 19,4\%, respectivamente, ambas para a porcentagem de concentrado de $52,7 \%$ (Fig. 2). Silva et al. (2005) também observaram efeito linear para a digestibilidade aparente total deste nutriente ao trabalharem com as mesmas proporções de concentrado do presente trabalho.

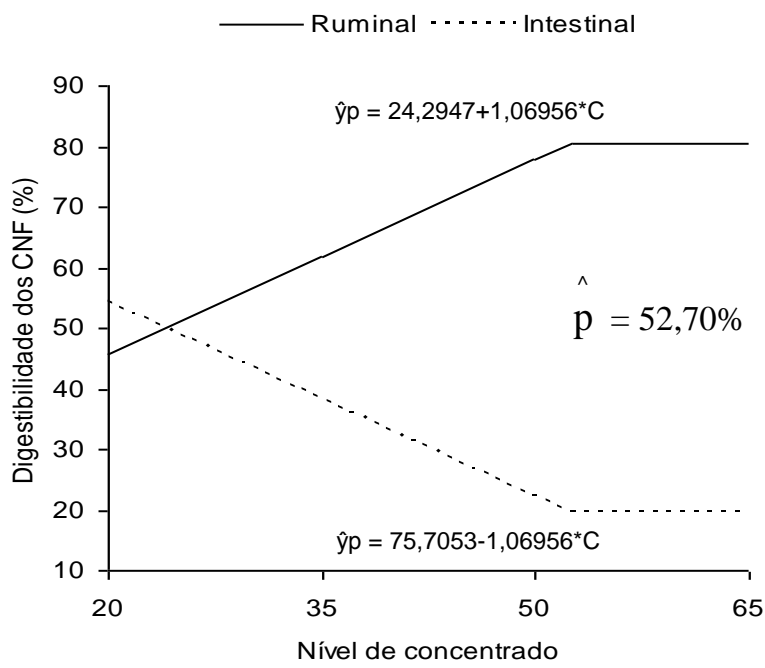

Figura 2. Representação gráfica do efeito linear-platô em função da porcentagem de concentrado nas dietas sobre a digestibilidade ruminal e intestinal dos carboidratos não fibrosos.

$\mathrm{O}$ pH ruminal não foi influenciado $(\mathrm{P}>0,05)$ pelo tempo de amostragem ou pela proporção de concentrado na dieta. Os valores médios de $\mathrm{pH}$ (Tab. 5) encontram-se acima da faixa inibitória ao desenvolvimento dos microrganismos celulolíticos, de 5,0 a 5,5, sugerida por Hoover (1986), resultado coerente com a digestibilidade ruminal da FDN, que não foi afetada pela variação da porcentagem de concentrado nas dietas (Tab. 4). Pereira et al. (2007), ao trabalharem com silagem de sorgo e concentrado nas mesmas proporções do presente estudo, observaram efeito quadrático do tempo de amostragem sobre o $\mathrm{pH}$ ruminal, estimando $\mathrm{pH}$ mínimo de 6,16, registrado em 4,28 horas após alimentação. 
A concentração de amônia ruminal não limitou a fermentação em nenhuma das dietas, pois, segundo Hoover (1986), concentração de amônia de $8,0 \mathrm{mg} / \mathrm{dL}$ favorece a digestão da fibra.
A concentração de amônia ruminal foi influenciada apenas pelo tempo de amostragem $(\mathrm{P}<0,05)$, estimando-se valor de máximo de 24,76mg/dL, 3,5 horas após a alimentação (Fig. 3).

Tabela 5. Valores médios de $\mathrm{pH}$ e de amônia $\left(\mathrm{N}-\mathrm{NH}_{3}\right)$ do líquido ruminal nos tempos 0,2 , 4 e 6 horas após a alimentação e respectivos coeficientes de variação (CV\%)

\begin{tabular}{|c|c|c|c|c|c|}
\hline \multirow{2}{*}{ Tempo } & \multicolumn{4}{|c|}{ Concentrado $(\%)$} & \multirow{2}{*}{$\mathrm{CV}(\%)$} \\
\hline & 20 & 35 & 50 & 65 & \\
\hline & \multicolumn{4}{|c|}{$\mathrm{pH}$} & \\
\hline 0 & 6,54 & 6,40 & 6,24 & 6,15 & 5,19 \\
\hline 2 & 6,71 & 6,60 & 6,44 & 6,37 & 4,34 \\
\hline 4 & 6,70 & 6,52 & 6,27 & 6,06 & 4,49 \\
\hline \multirow[t]{2}{*}{6} & 6,67 & 6,42 & 6,30 & 5,94 & 4,64 \\
\hline & \multicolumn{4}{|c|}{$\mathrm{N}-\mathrm{NH}_{3}(\mathrm{mg} / \mathrm{dL})$} & \\
\hline 0 & 17,56 & 16,35 & 21,05 & 20,78 & 25,83 \\
\hline 2 & 24,74 & 19,92 & 23,62 & 23,62 & 18,94 \\
\hline 4 & 25,11 & 23,67 & 23,67 & 25,22 & 11,70 \\
\hline 6 & 20,83 & 20,94 & 22,92 & 21,21 & 17,50 \\
\hline
\end{tabular}

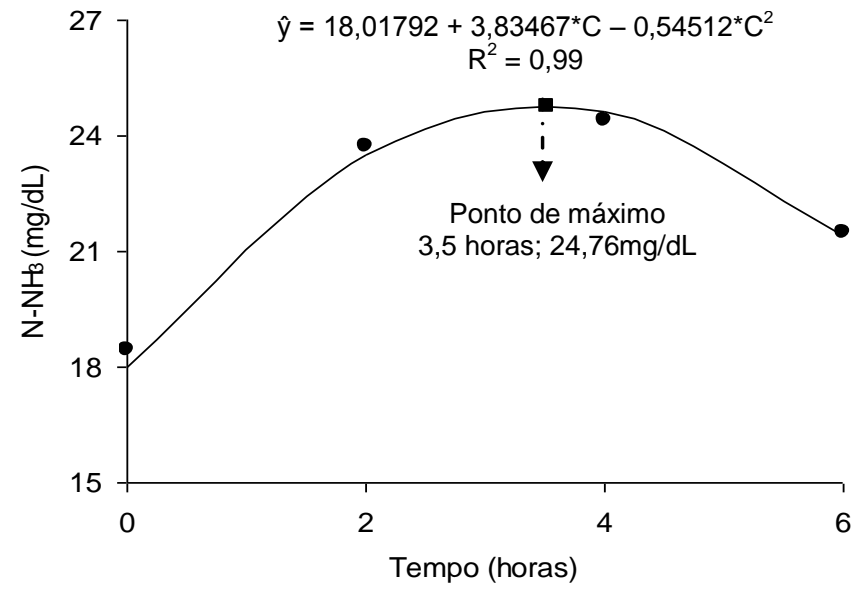

Figura 3. Representação gráfica da estimativa da concentração de $\mathrm{N}-\mathrm{NH}_{3}(\mathrm{mg} / \mathrm{dL})$ do líquido ruminal, em função dos tempos de amostragem. Significativo a $5 \%$ de probabilidade.

Valadares et al. (1997) encontraram resposta linear crescente para concentração de $\mathrm{N}-\mathrm{NH}_{3}$ ruminal com o aumento do concentrado das rações, decorrente da maior disponibilidade de energia no rúmen. Pereira et al. (2007) não verificaram efeito da proporção de concentrado sobre a concentração de amônia ruminal, mas observaram efeito quadrático de tempo de amostragem, a exemplo do presente trabalho.

$\mathrm{Na}$ Tab. 6, estão relatadas as médias dos valores estimados para as taxas de passagem, concentração de cromo no equilíbrio, tempo de retenção de sólidos no rúmen e fluxo de sólidos no rúmen e respectivas equações de regressão, ajustadas em função da porcentagem de concentrado.

Para a taxa de passagem, o tempo de retenção de sólidos no rúmen e o fluxo de sólidos no rúmen, os dados ajustaram-se a uma equação de regressão linear $(\mathrm{P}<0,05)$ em função da proporção de concentrado das dietas. Efeito semelhante foi encontrado por Silva (2003), que observou efeito linear crescente para taxa de passagem, com o aumento do concentrado nas dietas. 
Tabela 6. Médias dos valores estimados para taxa de passagem $(\mathrm{Kp})$, concentração de cromo no equilíbrio (A), volume ruminal (VLR), tempo de retenção de sólidos no rúmen (TR) e fluxo de sólidos no rúmen (FS), respectivas equações de regressão ajustadas em função da porcentagem de concentrado (C) e coeficientes de determinação $\left(\mathrm{r}^{2}\right)$

\begin{tabular}{|c|c|c|c|c|c|c|}
\hline \multirow{2}{*}{ Tempo } & \multicolumn{4}{|c|}{ Concentrado (\%) } & \multirow{2}{*}{ Equação } & \multirow{2}{*}{$r^{2}$} \\
\hline & 20 & 35 & 50 & 65 & & \\
\hline $\mathrm{Kp}^{1}$ & 0,0355 & 0,0371 & 0,0476 & 0,0514 & $\hat{\mathrm{y}}=0,0264543+0,000387133^{*} \mathrm{C}$ & 0,93 \\
\hline$A^{\frac{1}{2}}$ & 2060,48 & 1865,69 & 2403,73 & 1772,95 & $\hat{y}=2025,71$ & --- \\
\hline VLR $^{3}$ & 5,63 & 6,22 & 4,83 & 6,54 & $\hat{y}=5,80$ & --- \\
\hline $\mathrm{TR}^{4}$ & 28,1373 & 26,9397 & 21,0305 & 19,4477 & $\hat{\mathrm{y}}=32,9492-0,213187 * \mathrm{C}$ & 0,93 \\
\hline $\mathrm{FS}^{4}$ & 2,4363 & 2,7942 & 2,8103 & 4,0966 & $\hat{\mathrm{y}}=1,62771+0,0330976^{*} \mathrm{C}$ & 0,77 \\
\hline
\end{tabular}

* Significativo a $5 \%$ de probabilidade, pelo teste $\mathrm{F}$.

${ }^{1}\left(\mathrm{~h}^{-1}\right) ;{ }^{2}(\mathrm{mg} / \mathrm{kgMS}) ;{ }^{3}(\mathrm{kgMS}) ;{ }^{4}(\mathrm{~h}) ;{ }^{5}(\mathrm{kgMS} / \mathrm{h})$

Segundo Owens e Goetsch (1993), a taxa de passagem para fluidos de partículas de concentrado e de forragem varia com a ingestão e com a proporção de forragem na dieta. Ainda que a taxa de passagem para partículas de concentrado e de forragem tenda a aumentar com a ingestão de alimento, as oscilações diferem de forma que a taxa de passagem para partículas de concentrado excede aquela para forragens em aproximadamente $10 \%$. Assim, dietas que contenham maior proporção de concentrado apresentam maior taxa de passagem e menor taxa de retenção de sólidos no rúmen, comparadas àquelas com menor proporção de concentrado.

\section{CONCLUSÕES}

Considerando-se os diferentes parâmetros ruminais, recomenda-se para bovinos de corte, alimentados com dietas à base de silagem de capim-mombaça, porcentagens de concentrado entre 53 e $63 \%$.

\section{REFERÊNCIAS BIBLIOGRÁFICAS}

BOLSEN, K.K.; LIN, C.; BRENT, B.E. et al. Effect of silage additives on the microbial succession and fermentation process of alfafa and corn silages. J. Dairy Sci., v.75, p.3066-3083, 1992.

CARDOSO, R.C.; VALADARES FILHO, S.C.; COELHO DA SILAVA, J.F. et al. Consumo e digestibilidades aparentes totais e parciais de rações contendo diferentes níveis de concentrado, em novilhos F1 Limousin x Nelore. Rev. Bras. Zootec., v.29, p.1832-1843, 2000.
CARVALHO, A.U.; VALADARES FILHO, S.C.; COELHO DA SILVA, J.F. et al. Níveis de concentrado em dietas de zebuínos. 1. Consumo e digestibilidade aparente. Rev. Bras. Zootec., v.26, p.986-995, 1997.

ELLIS, W.C.; MATIS, J.H.; HILL, T.M. et al. Methodology for estimating digestion and passage kinetics of forages. In: FAHEY, G.C.; COLLINS, M.; MERTENS, D.R. et al. (Eds.). Forage quality, evaluation and utilization. Madison: American Society of Agronomy, National Conference on Forage Quality, Evaluation and Utilization, 1994. p.450-493.

ERDMAN, R. Silage fermentation: Characteristics affecting feed intake. In: NATIONAL SILAGE PRODUCTION CONFERENCE, Syracuse, WY. Proceedings... Syracuse : NRAES-67, 1993. p.210.

EUCLIDES FILHO, K.; EUCLIDES, V.P.B.; FIGUEIREDO, G.R. Avaliação de animais nelores e seus mestiços com Charolês, Fleckiveh e Chianina, em três dietas. 1. Ganho de peso e conversão alimentar. Rev. Bras. Zootec., v.26, p.6672, 1997.

GESUALDI Jr., A.; PAULINO, M.F.; VALADARES FILHO, S.C. et al. Níveis de concentrado na dieta de novilhos $\mathrm{F} 1$ Limousin $\mathrm{x}$ Nelore em confinamento: Consumo, conversão alimentar e ganho de peso. Rev. Bras. Zootec., v.29, p.1458-1466, 2000.

HALL, M.B. Calculation of non-structural carbohydrate content of feeds that contain nonprotein nitrogen. Gainesville: University of Florida, 2000. p.A-25 (Bulletin 339).

HOOVER, W.H. Chemical factors involved in ruminal fiber digestion. J. Dairy Sci., v.69, p.27552766, 1986 
ÍTAVO, L.C.V.; VALADARES FILHO, S.C.; SILVA, F.F. et al. Consumo e digestibilidade aparentes totais e parciais de nutrientes em novilhos alimentados com dietas contendo vários níveis de concentrado. Rev. Bras. Zootec., v.31, p.1543-1552, 2002.

KÖEPPEN, W. Climatologia. Buenos Aires: Panamericana, 1948. 478p.

McDONALD, P.; HENDERSON, A.R.; HERON, S.J.E. The biochemistry of silage. 2.ed. Aberystwyth: Chalcombe Publications, 1991. 340p.

MERTENS, D.R. Regulation of forage intake. In: FAHEY, G.C.; COLLINS, M.; MERTENS, D.R. et al. Forage quality, evaluation and utilization. Madison: American Society of Agronomy, National Conference on Forage Quality, Evaluation and Utilization, 1994. p.450-493.

MUCK, R.E.; PITT, R.E. Ensiling and its effect on crop quality silage. In: SILAGE PRODUCTION FROM SEED TO ANIMAL, 67., 1993. New York. Proceedings... New York: NRAES, 1993. p.57-66.

NUTRIENT requirements of beef cattle. $7 \mathrm{ed}$. Washington, DC: National Academy of Sciences, 2001. 381p.

OWENS, F.N.; GOETSCH, A.L. Fermentación ruminal. In: CHURCH, D.C. El ruminante, fisiologia digestiva y nutrición: Zaragoza: Acríbia, 1993. p.159-190.

PELL, A.N.; SCHOFIELD, P. Computerized monitoring of gas production to measure forage digestion in vitro. J. Dairy Sci., v.76, p.1063-1073, 1993.

PEREIRA. D.H.; PEREIRA. O.G.; SILVA. B.C. et al. Intake and total and partial digestibility of nutrients, ruminal $\mathrm{pH}$ andammonia concentration and microbial efficiency in beef cattle fedwith diets containing sorghum (Sorghum bicolor (L.) Moench) silage and concentrate in different ratios. Livest. Sci., v.107, p.53-61. 2007.

RESENDE, F.D.; QUEIROZ, A.C.; OLIVEIRA, J.V. et al. Bovinos mestiços alimentados com diferentes proporções de volumoso:concentrado. 1. Digestibilidade aparente dos nutrientes, ganho de peso e conversão alimentar. Rev. Bras. Zootec., v.30, p.261-269, 2001.
RIBEIRO, K.G.; GARCIA, R.; PEREIRA O.G. et al. Consumo e digestibilidades aparentes total e parcial de nutrientes, em bovinos recebendo rações contendo feno e capim-tifton 85 de diferentes idades de rebrota. Rev. Bras. Zootec., v.30, p.573580,2001

SILVA, D.J.; QUEIRÓZ, A.C. Análise de alimentos: métodos químicos e biológicos. 3.ed. Viçosa: UFV, 2002. 235p.

SILVA, B.C.; PEREIRA, O.G.; PEREIRA, D.H. et al. Consumo e digestibilidade aparente total dos nutrientes e ganho de peso de bovinos de corte alimentados com silagem de Brachiaria brizantha e concentrado em diferentes proporções. Rev. Bras. Zootec., v.34, p.268-279, 2005.

SILVA, B.C. Silagem de Brachiaria brizantha $\mathrm{cv}$. Marandu e concentrado em diferentes proporções na dieta de bovinos de corte. 2003. 65f. Dissertação (Mestrado) - Universidade Federal de Viçosa, Viçosa, MG

TIBO, G.C.; VALADARES FILHO, S.C.; VALADARES, R.F.D. et al. Níveis de concentrado em dietas de novilhos F1 Simental x Nelore. 1. consumo e digestibilidade. Rev. Bras. Zootec., v.29, p.910-920, 2000.

VALADARES， R.F.D.; GONÇALVES， L.C.; SAMPAIO, I.B.M. et al. Níveis de proteína em dietas de bovinos. 3. pH, amônia e eficiência microbiana. Rev. Bras. Zootec., v.26, p.1264-1269, 1997.

VAN SOEST, P.J. Nutritional ecology of the ruminants. 2.ed. Ithaca: Cornell University, 1994. 476p.

VIEIRA, P.F. Efeito do formaldeído na proteção de proteínas e lipídios em rações de ruminantes. 1980. 98f. Tese (Doutorado) - Universidade Federal de Viçosa, Viçosa, MG.

WILLIANS, C.H.; DAVID, D.J.; IISMAA, O. The determination chromic oxide in feces samples by atomic absorption spectrophotometry. J. Agric. Sci., v.59, p.381-385, 1962 .

Este trabalho é parte da dissertação de mestrado do primeiro autor, apresentada ao Programa de pósgraduação em Zootecnia da UFV, parcialmente financiada pelo CNPq e FAPEMIG. 